\title{
CONSTRUINDO O CONHECIMENTO DA GEOGRAFIA FÍSICA A PARTIR DA PRODUÇÃO DA REVISTA GEOGRÁFICA TP: RELATO DE EXPERIÊNCIA NA ESCOLA TEREZINHA PAULINO
}

\author{
Ana Beatriz Câmara Maciel ${ }^{(a)}$,Zuleide Maria Carvalho Lima ${ }^{(b)}$,Yuri Marques Macedo ${ }^{(c),}$ Marcelo \\ dos Santos Chaves ${ }^{(\mathrm{d})}$ \\ (a) Departamento de Geografia, UFRN, E-mail: anaufrn@yahoo.com.br \\ (b) Departamento de Geografia, UFRN, E-mail: zuleide@ ufrnet.br \\ (c) Departamento de Geografia, UFRN, E-mail: yurimmacedo@ hotmail.com \\ (d) Departamento de Geografia, UFRN, E-mail: mschaves2007@gmail.com
}

EIXO: GEOGRAFIA FÍSICA: CURRÍCULO, FORMAÇÃO E PRÁTICA DE ENSINO

\begin{abstract}
Resumo
O artigo fez parte da culminância de um projeto de ensino em Geografia Física desenvolvido na Escola Mun. Prof. Terezinha Paulino, Parque dos Coqueiros, bairro de Nossa Senhora da Apresentação em Natal/RN, sob a coordenação dos professores de geografia, com a colaboração dos docentes do Dep. Geografia da UFRN. O objetivo principal foi desenvolver junto aos discentes a produção de uma revista na qual tinham como temáticas os conteúdos da geográfica física ministrada durante o ano nas turmas dos $9^{\circ}$ anos A, B e C (Ensino Fundamental II). Com o intuito de elaborar e incentivar a leitura e produção de uma revista com os principais fatos, acontecimentos, vivências, ocorrências na comunidade local, relacionados aos conteúdos referentes à geografia física. A metodologia utilizada foi o levantamento bibliográfico direcionado aos conteúdos abordados; e a exposição dos mesmos, se deu por filmes, slides, imagens, trabalhos em grupos e individuais, palestras com professores de Geografia da UFRN, e ao final foi exposto na Mostra de Cultura da Escola e na CIENTEC em 2016. Durante o ano, foram elaborados vários textos correspondentes aos trabalhos na disciplina de Geografia Física, e isso contribuiu para a produção textual dos alunos, como também a descrição das atividades de campo.
\end{abstract}

Palavras chave: Geografia Física; Ensino-Aprendizagem.

\section{Introdução}

Perante aos problemas vivenciados na rede pública de ensino, os professores de Geografia da Rede Pública de Natal procuraram levar aos discentes a produzir um material com os conteúdos da Ciência Geográfica, enfatizando a Geografia Física, aliado as questões atuais vivenciadas pelo nosso aluno em sua comunidade. Sendo assim, para aproximar a produção da escrita das necessidades enfrentadas no nosso dia-a-dia, o caminho atual encontrado foi enfocar o desenvolvimento dos comportamentos dos nossos alunos (futuros leitores e escritores) e sua curiosidade com a disciplina da Geografia Física.

Desta forma, proporcionar os discentes a participar de forma eficiente de atividades da vida social que envolva a leitura e a escrita é bastante satisfatório. Assim, grandes professores conseguem envolver seus discentes para que eles se sintam parte da atividade. 
Noticiar um fato num jornal, ensinar os passos para fazer uma sobremesa ou argumentar para conseguir que um problema seja resolvido por um órgão público: cada uma dessas ações envolve um tipo de texto com uma finalidade, um suporte e um meio de veiculação de objetivos específicos. Assim, conhecer esses aspectos é condição mínima para decidir, enfim, o que escrever e de que forma fazer isso. Fica evidente que não são apenas as questões gramaticais ou notacionais (como por exemplo, a ortografia) que ocupam o centro das atenções na construção da escrita, mas a maneira de elaborar o discurso.

Verificou-se outro ponto fundamental nessa produção de atividades a elaboração de texto: quem vai ler. E, nesse caso, você não conta. "Entregar um texto para o professor é cumprir tarefa", argumenta Fernanda Liberali, da Pontifícia Universidade Católica de São Paulo. "Escrever não é fácil. Para que o aluno fique estimulado com a proposta, é preciso que veja sentido nisso." O objetivo é fazer com que um leitor ausente no momento da produção compreenda o que se quis comunicar - e esse desafio requer diferentes aprendizagens. Foi pensando nisso que foi proposto a produção de uma Revista Geográfica para as turmas dos $9^{\circ}$ anos A, B e C da Escola Municipal Professora Terezinha Paulino (EMPTP), totalizando 103 alunos envolvidos na execução do projeto. Destaca-se o bom relacionamento entre os alunos, os professores, gestores e funcionários envolvidos no projeto. Com a escrita dos alunos pode-se observar uma aproximação com os conceitos geográficos e as práticas didáticas da geografia física e suas relações com o meio ambiente.

\section{Objetivo Geral}

Incentivar a produção de uma revista com base nos conceitos geográficos - com ênfase na Geografia Física, elencando os principais fatos, acontecimentos, vivências dos discentes, docentes e da comunidade local da Escola Municipal Professora Terezinha Paulino, localizada no Conjunto Parque dos Coqueiros no Estado do Rio Grande do Norte.

\subsection{Objetivos Específicos}

- Elaborar uma revista com as temáticas da Ciência Geográfica - enfatizando a Geografia Física;

- Escrever as temáticas escolhidas e conceituá-las;

- Contribuir para a sociabilização entre os discentes;

- Propor a interação entre a escola-casa-comunidade;

- Desenvolver nos alunos as suas habilidades e competências - desenho, dança, leitura, criação, paródias, toques de instrumentos musicais, entre outros;

- Explanar a importância da produção da revista para o aluno e sua relação com o meio ambiente.

\section{Caracterização da Escola Municipal Terezinha Paulino (EMPTP)}


O projeto da Revista Geográfica TP (Terezinha Paulino) foi desenvolvido na Escola Municipal Profa Terezinha Paulino de Lima, localizada no Bairro: Nossa Senhora da Apresentação/Conjunto Parque dos Coqueiros na Cidade de Natal/RN (Figura 1). A referida instituição pertence à Região Administrativa Norte, ela é a maior zona administrativa da cidade do Natal, tanto em extensão territorial quanto em população.

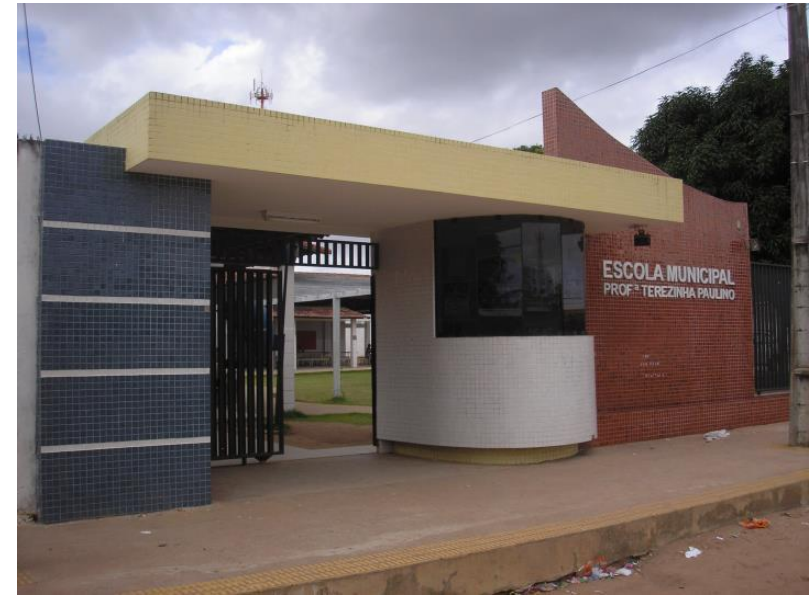

Figura 1 - Fachada da Escola Municipal Professora Terezinha Paulino de Lima. Foto: Lúcia Salviano (Ago./2016).

A escola de médio porte é responsável pelo atendimento de mais de mil alunos e parte deles residem em comunidades periféricas circunvizinhas. As Modalidades de Ensino ofertadas são: Ensino Fundamental II $\left(6^{\circ}\right.$ ao $9^{\circ}$ ano) nos turnos matutino e vespertino e Educação de Jovens e Adultos (EJA - Nível II ao Nível IV) no noturno. O corpo docente é completo e formado em sua maioria por professores concursados e temporários.

Constatou-se que a escola possui Projeto Político Pedagógico bem estruturado e atualizado a cada dois anos. Os espaços da escola são bem cuidados e possuem em sua infraestrutura. Quanto às dependências são elas: 12 salas de aulas e 4 salas atividades diferenciadas, sala de Diretoria, sala de professores, laboratório de informática, sala de recursos multifuncionais para Atendimento Educacional Especializado (AEE), quadra de esportes coberta, cozinha, biblioteca, sala de leitura, banheiro dentro do prédio, sala de secretaria, refeitório, despensa e área verde, conforme a figura 2 (Censo Escolar, 2016). 

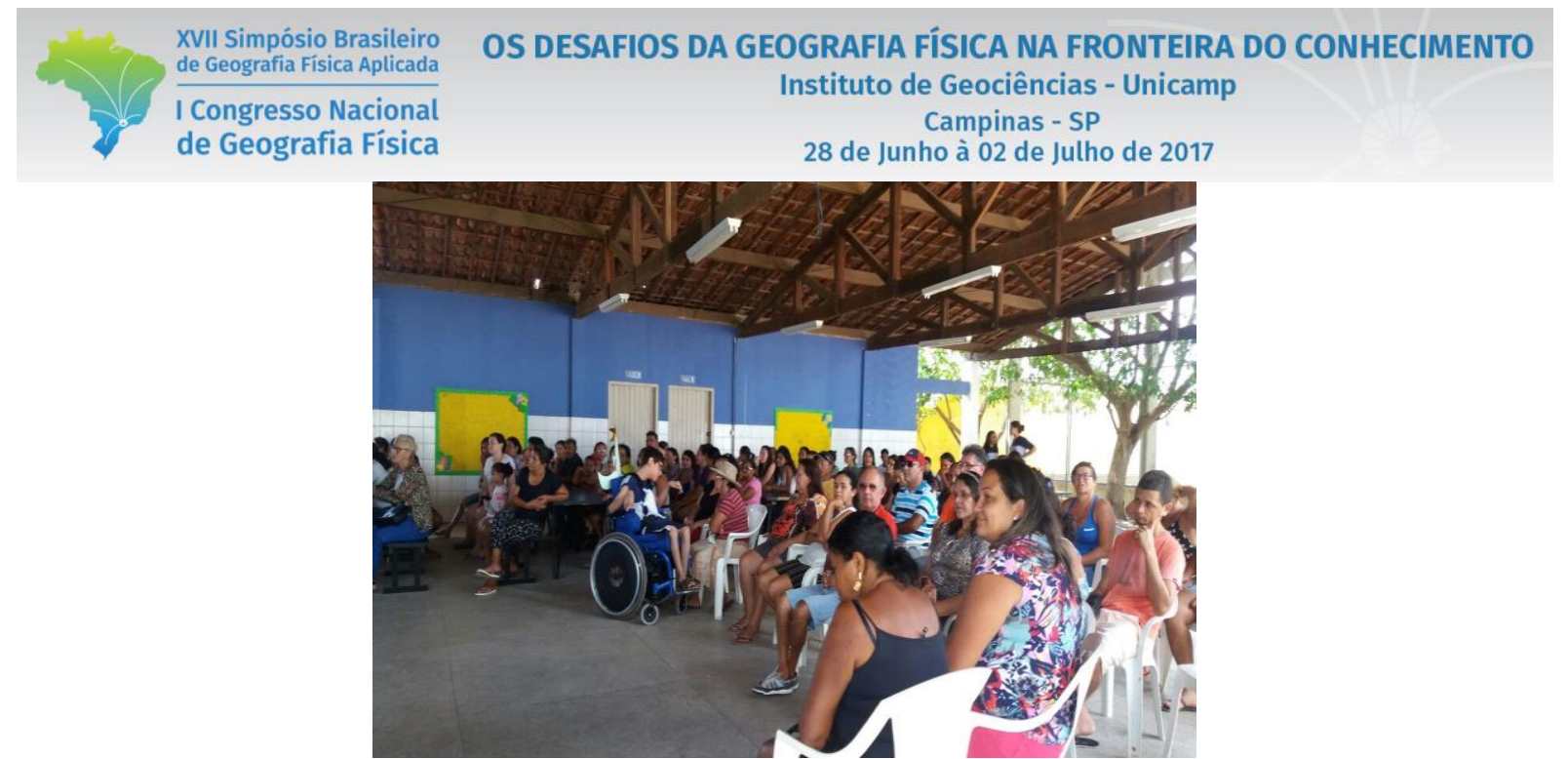

Figura 2 - Atividades desenvolvidas no Pátio da Escola Municipal Professora Terezinha Paulino de Lima. Foto: Ana Beatriz Maciel (Out./2016).

A Escola Municipal Professora Terezinha Paulino de Lima, foi fundada em 11 de Março de 1993. Antes de sua fundação, este local era sede de uma empresa de construção. Esta empresa foi responsável, pela construção do conjunto habitacional Parque dos Coqueiros. A empresa deixou o local e a professora Terezinha Paulino de Lima, que por sua vez vendo a carência da população, decidiu usar o prédio para dar aulas. Pois não havia escola nas proximidades do bairro. A situação do prédio era muito precária. Havia duas salas muito pequenas e apenas um banheiro que ficava em uma das salas.

Após o falecimento da Professora Terezinha, aos 44 anos de idade, no dia 31 de Janeiro de 1993, a prefeitura de Natal, oficialmente fundou a escola em sua homenagem. Ao longo do tempo, a instituição foi melhorando cada vez mais, tanto em estrutura como em ensino, e em 2014 foi titulada uma das melhores escolas da rede pública da capital do RN. Verifica-se a necessidade de mais investimentos para melhorar a qualidade dos equipamentos e possibilitar o desenvolvimento das aulas dos professores da instituição.

A comunidade do Parque dos Coqueiros e bairros adjacentes são bem presentes nas atividades desenvolvidas na Escola. Os pais sempre são convidados a participarem de vários eventos, projetos nos fins de semana, em reuniões com a gestão e os professores para discutirem a situação dos alunos.

\section{Referencial Teórico}

Nesse tópico será abordado os conceitos bases da geografia, como Espaço e Paisagem, que ao longo do ano de 2016, foi sendo trabalhado dentro dos conteúdos programados nos PCNs para a Geografia. E como estes conceitos estão sendo abordados em sala de aula, e como isso contribui para a construção do conhecimento cientifico eficaz dos alunos.

\subsection{Construindo os conceitos base da Geografia no Ensino Fundamental II}


O ensino da Geografia Física vem sofrendo modificações ao longo do tempo, e vem sendo questionado em consequência de vários fatores, entre eles, a discussão sobre os conteúdos e critérios que devem ser trabalhados nas escolas de Ensino Fundamental e Médio, juntamente com a atualização dos docentes. Essas mudanças redimensionaram a forma de ensinar e o que deve ser ensinado na sala de aula, levando o professor a buscar novas maneiras de avaliar e analisar, além do conteúdo dos livros didáticos, os valores presentes no ato de ensinar, com também avaliar o meio ambiente no seu entorno, como afirma Freire (2009).

Nesse sentido, o educador deve estar disposto a utilizar as novas técnicas e metodologias para elaborar as suas aulas, pois, o mesmo se depara com um público cada vez mais exigente, a espera de mais conhecimento sobre o espaço geográfico e, consequentemente, das paisagens vivenciadas pelos mesmos.

Dessa forma, o livro didático vem sendo usado pelos educadores como um dos instrumentos fundamentais de ensino como aborda Adas (2014) e o de Rama (2013), mostrando a importância de relacionar os conceitos da geografia física e a vivência dos discentes. Portanto, cabe ao professor à análise crítica na utilização do livro didático de Geografia, não permitindo com que os discentes fiquem alienados com os conceitos e/ou definições prontas. Isso acaba corroborando para a formação cultural e social, já que se mantém como o recurso presente em sala de aula e, sendo esse, a principal fonte de atualização e de reflexão (VEDOVOTE, 2013).

Sendo assim, caberá ao professor discutir em sala como se construiu os conceitos base da geografia, e como deve ser empregado na atualidade, pois o estudo da paisagem, por exemplo, não deve se limitar à mera constatação e descrição dos fenômenos que a constituem. Mas, será de enorme importância pedagógica poder explicar e compreender todos os processos de interação entre a sociedade e a natureza, situando-as em diferentes escalas parciais e temporais, comparando-as e dando-lhes significados.

Diante disso, o conceito de paisagem geográfica vem sendo muito trabalhado nas últimas décadas, principalmente relacionadas ao meio ambiente. Isto se deve a importância deste conceito para a Geografia. Nesse contexto, destaca-se que: "a categoria paisagem, porém, tem um caráter específico para a geografia, distinto daquele utilizado pelo senso comum ou por outros campos do conhecimento. É definida como sendo uma unidade visível do território, que possui identidade visual, caracterizada por fatores de ordem social, cultural e natural, contendo espaços e tempos distintos; o passado e o presente" (BRASIL - PCNs, 1997, p. 11).

A noção de paisagem tem sido amplamente debatida em muitos ramos da ciência, principalmente entre os geógrafos, arquitetos e urbanistas que tem contribuído com diversos estudos e pesquisa dessa natureza, sempre buscando compreender as relações que se estabelecem entre o ser humano e o seu entorno, vem 
sendo bastante discutidas nas leituras e interpretações de Adas (2014), Vedovote (2013) e também em Rama (2013).

Mediante isso, o espaço como categoria, pois as paisagens estão inseridas nele, sendo transformadas a todo o momento. Dessa forma, é imprescindível deixar de abordar sobre os conceitos de espaço e paisagem na sala de aula do Ensino Fundamenta II. Verifica-se que Santos (1985) e Santos (2008), trabalha com o espaço e a paisagem, descrevendo o conceito e os elementos que compõem cada um e como eles agem de maneira integrada. Segundo Santos (1985), o conceito de espaço consegue fazer todas as possíveis relações existentes, e de acordo com isso, afirma:

Espaço deve ser considerado como um conjunto indissociável de que participa, de um lado, certo arranjo de objetos geográficos, objetos naturais e objetos sociais e, de outro, a vida que os preenche e os anima, ou seja, a sociedade em movimento. (SANTOS, 1985, p. 27)

Ao analisar e compreender esse conceito, acreditamos que o mesmo dá fundamentos aos discentes do Ensino Fundamental II (como categorias do método geográfico que são: estrutura, processo, função e forma) para o que está sendo desenvolvido no trabalho, ou seja, fazer a relação do espaço com o meio natural e com a sociedade, mas também o porquê desta está transformando o espaço geográfico. Dessa forma, é necessário que ocorra uma abordagem centrada no espaço de vivência dos alunos.

Na Geografia destaca-se o norte-americano Carl Sauer, com sua obra intitulada The Morphology of Landscape, de 1925, onde este utiliza o termo paisagem para estabelecer o conceito unitário da Geografia, considerada como sendo uma fenomenologia das paisagens. Sauer, na sua obra supracitada, foi um dos primeiros geógrafos a tratar a geografia de maneira integrada, privilegiando, ao mesmo tempo, os fatores naturais e sociais, inserindo a compreensão da categoria paisagem como elo integrador desses fatores (Figura 3).

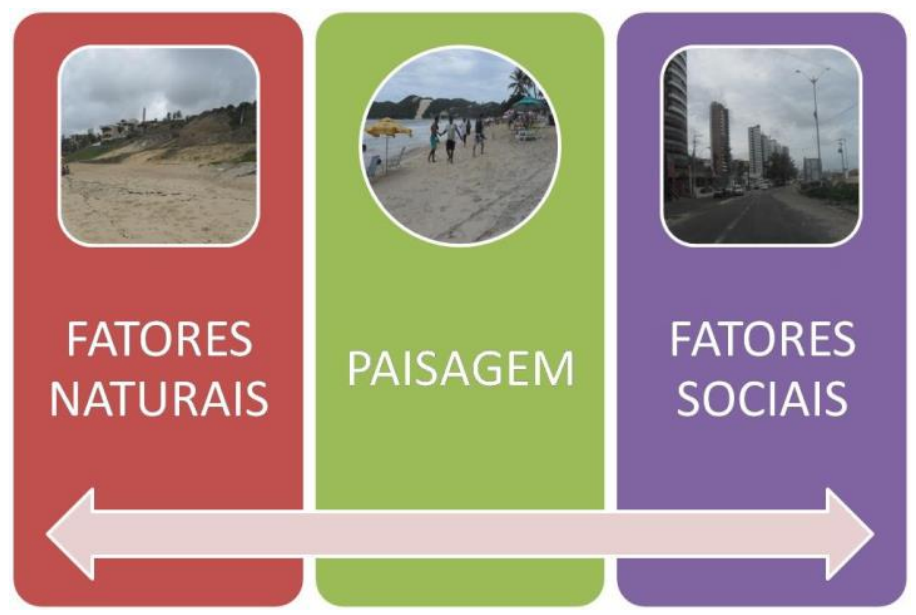

Figura 3: Paisagem - integração entre os fatores naturais e sociais. Elaboração: Ana Beatriz C. Maciel (Dez/2016). 
Dessa maneira, Sauer (1925 apud CORRÊA, 1998, p.13) define a paisagem como sendo,

Uma área composta por associação distinta de formas, ao mesmo tempo físicas e culturais, onde sua estrutura e função são determinadas por formas integrantes e dependentes, ou seja, a paisagem corresponde a um organismo complexo, feito pela associação especifica de formas e apreendido pela análise morfológica, ressaltando que se trata de uma interdependência entre esses diversos constituintes, e não de uma simples adição, e que se torna conveniente considerar o papel do tempo.

No entanto, Sauer (1925 apud CORRÊA, 1998), no início do século XX, já afirmava que o conceito de paisagem era algo complexo e que envolvia todos os elementos, sejam eles naturais e sociais. Esse autor ainda ressalta que qualquer definição da mesma, única, desorganizada ou não-relacionada, não tem valor científico, e divide o conteúdo da paisagem em duas partes: o "sítio", que representa o somatório dos recursos naturais; e a sua expressão cultural, ou a marca da ação do homem sobre uma área.

A partir da década de 1980 intensificaram-se os diversos estudos relacionados à paisagem, numa abordagem sistêmica e integrada dos componentes da natureza. Foram vários os trabalhos relacionados com as questões ambientais e de cunho aplicativo, utilizando-se de metodologias, como as propostas de Bertrand e Tricart para a classificação da paisagem.

Nesse mesmo cenário, surgem trabalhos de Bolós (1981) e Jardi (1990), que abordam os conceitos relativos às Teorias do Geossistema de Sotchava e da Ecodinâmica de Tricart, elencando o conceito de paisagem integrada, como sendo o resultado da interação do geossistema (elementos, estrutura e dinâmica) com sua localização espacial e temporal. Então, a abordagem Geossitêmica procura entender as variações paisagísticas como produto histórico dos fluxos de matéria e energia, abarcando a ação do homem.

Embora o geossistema seja um fenômeno natural, todos os fatores econômicos e sociais influenciam na sua estrutura, consistindo assim, além dos fatores naturais, os fatores ligados a ação antrópica também são levados em consideração durante o seu curso e suas descrições verbais ou temáticas. Modelos e gráficos do geossistemas refletem também parâmetros econômicos e sociais.

De acordo com as pesquisas, a Teoria Geossitêmica foi organizada por Viktor Borisovich Sotchava, no qual afirmava que o geossistema é uma dimensão do espaço terrestre onde os mais diversos componentes naturais se encontram em conexões sistêmicas uns com os outros. Ocupando assim, um espaço de grande importância junto com a região, o meio e o espaço, a paisagem sempre esteve presente na linha temática da geografia física, ela responde à orientação da geografia para o concreto, o visível, a observação do terreno, enfim, para a percepção direta da realidade geográfica, a mesma é para o geógrafo a porta de entrada para o mundo. Segundo Sotchava (1976) aborda que os geossistemas são formações naturais, experimentando, sob certa forma, o impacto dos ambientes social, econômico e tecnogênico. 


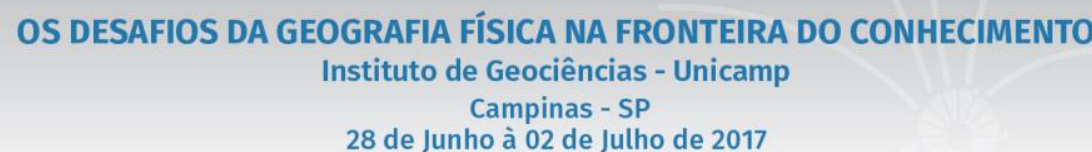

Diante disso, podemos então afirmar que o geossistema não se subdivide infinitamente, pois depende de uma organização geográfica. Dentro desse mesmo pensamento, Bolós afirma que:

O objetivo do estudo da geografia e da paisagem deve ser visto como uma realidade integrada, onde os elementos abióticos, bióticos e antrópicos aparecem associados de tal maneira, que os conjuntos podem ser trabalhados como um modelo de sistema. (BOLÓS, 1981 apud GUERRA, 2006, p. 113).

Nesse fragmento é importante destacar que o objeto da geografia é o espaço pelo qual deve ser analisado e compreendido em conjunto com os processos naturais e antrópicos. Esses elementos estão dentro de um sistema. Conforme aponta o autor, é na análise sistêmica e no estudo da paisagem que a geografia física se amolda ou se adapta a essa tendência através dos estudos do geossistema - corresponde a um modelo teórico da mesma forma como o ecossistema, ou seja, não existindo na prática e correspondendo a uma construção mental e subjetiva da realidade. Assim, o referido autor enfatiza bem a utilização do método sistêmico na análise da paisagem, e consequentemente, da Geografia Física.

Nesse contexto, as paisagens são, em quase todas as abordagens dos séculos XIX, XX e XXI, entidades espaciais que dependem da história econômica, cultural e ideológica de cada grupo regional e de cada sociedade e, se compreendidas como portadoras de funções sociais, não são produtos, mas processos de conferir ao espaço significados ideológicos ou finalidades sociais com base nos padrões econômicos, políticos e culturais vigentes. E estudá-la é antes de tudo apresentar um problema de método.

Diante disso, Bertrand (1972 apud OLIVEIRA, 1998, p. 63), entende que a paisagem é:

Resultado da combinação dinâmica, portanto instável, de elementos físicos, biológicos e antrópicos que, reagindo dialeticamente uns sobre os outros, fazem da paisagem um conjunto único e indissociável, em perpétua evolução, numa porção do espaço, tem-se que pensar em normas legais que contemplem tanto o complexo dos elementos naturais, quanto o de elementos construídos, ou ainda, de ambos, considerados na sua dinâmica e identificados, como patrimônio paisagístico da coletividade.

Conforme o exposto, a paisagem é um resultado de forças naturais e humanas que constitui um fato físico e cultural, os quais estão interligados no espaço em um determinado período (tempo), entendendo esse resultado como o produto e não como uma imagem. Deve ser entendida também como uma estrutura morfológica determinada, que pode ser mensurada, quantificada e qualificada.

Diante dessas considerações, Bertrand (1972 apud OLIVEIRA, 1998), afirma que a paisagem não pode ser configurada como uma realidade imóvel, já que a presença do homem nela se estampa, tanto na área urbana como na área rural, através de sua ação sobre os diversos componentes, os quais irão produzir os frutos da sua própria cultura.

Torna-se evidente que a sociedade humana vem, há milhares de anos, sendo responsável pela criação e transformação de segmentos inteiros de paisagens, tais como: enormes canais de irrigação, a construção de grandes espigões, pontes, viadutos - as cidades em geral. Isso deixa claro que são resultados de ações e 
lógicas sociais, que foram decididas no intuito de prover abrigo, alimento, transporte, energia, lazer, entre outros, para toda a comunidade. Isso pode ser analisado em Almeida (1993), quando afirma que as marcas do tempo, impressas na paisagem, revelam uma construção histórica cheia de arte e lembrança que são facilmente identificadas por aqueles que ali vivem, pois o lugar é o espaço da vida.

Entretanto, há de se destacar que o espaço geográfico não é estático, mas sim, transformado quase que diariamente a fim de atender as novas exigências promovidas pela sociedade. Assim, o mesmo, podem não ser o mesmo de amanhã, em virtude da rápida transformação dessas áreas. A este respeito, deve-se destacar a crescente tomada de consciência por parte de profissionais, pesquisadores, professores envolvidos com a questão ambiental e ao planejamento, em resgatar áreas até então já degradadas e popularizar o conhecimento das ciências da Terra para os alunos.

De forma geral, hoje é possível perceber a existência conceitual de várias paisagens, em forma de região, território, lugar, etc. E discutir essa pluralidade conceitual e cognitiva é, no âmbito da geografia física, sem dúvida, um grande desafio. Para a esfera da geografia física, já se percebe uma grande mudança ao se focar a problemática da paisagem, levando em conta o homem, muito embora possa aparecer de forma denotativa e funcional, enquanto para a geografia cultural, há algum tempo, as paisagens são conotativas, cheios de valores subjetivos e relacionados às culturas.

Na sala de aula, há várias décadas, a Geografia vem convivendo com a dicotomia entre a Geografia Física e a Humana, sendo que isso reflete no ensino-aprendizagem, visto que uma grande parcela dos docentes apoia-se em livros didáticos, muita das vezes, inadequados por abordar o quadro natural separado do social e que os conteúdos de Geografia Física tende a ser uma mera descrição das paisagens.

Assim, com isso, o professor, como articulador do processo de ensino-aprendizagem, tem o dever de submeter o aluno a questionamentos, induzi-lo a refletir criticamente sobre o conteúdo que está sendo assimilado (LIBÂNEO, 2002). Conforme aponta o professor Libâneo (1994) pode-se afirmar que será através da ação educativa o meio social exerce influências sobre os indivíduos e estes, ao assimilarem e recriarem essas influências tornam-se capazes de estabelecer uma relação ativa e transformadora em relação ao meio social (LIBÂNEO, 1994, p. 17). Esta discussão pode ser levada para a sala de aula, permitindo que o aluno tenha uma visão mais ampla e relacional das paisagens com os demais elementos que podem modificar o espaço geográfico. Pois, a função do docente é mediar e fazer com que seus alunos possam refletir naquilo que estão sendo trabalhados.

O estudo da paisagem, assim como os demais conceitos da geografia, é fundamental no processo de educação geográfica. Lamentavelmente, tal conceito é, na maioria dos casos, trabalhado de maneira restrita quanto ao seu significado, riqueza e contribuição para a percepção da realidade socioespacial 


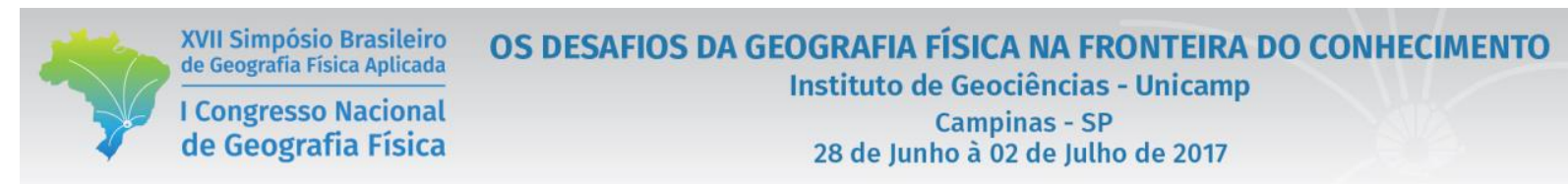

vivenciada pelo aluno. Do meio acadêmico não cessam as contribuições teóricas e práticas para o educador, porém, o mesmo ainda se encontra aprisionado pelo livro didático, que se tornou quase uma "bíblia" para o professor e, em muitos casos, este apresenta um proposta de ensino ultrapassada e distante do que se deveria ser realmente o ensino da geografia física.

Diante da abordagem feita nos livros didáticos sobre o conceito de paisagem é necessário analisarmos como este está sendo ministrado, como ensiná-lo de maneira que desperte no discente uma visão mais complexa, principalmente no ensino fundamental II. Tendo em vista que é um assunto essencial no processo de ensino-aprendizagem da Ciência Geográfica, por discutir tanto o quadro natural, quanto o social de forma integrada.

Desta forma, colaborando para que a discussão da dicotomia entre Geografia Física e Geografia Humana seja ultrapassada de modo que se tenha uma coesão entre o quadro natural e o social no ensino de Geografia, permitindo uma visão global das relações que ocorrem no espaço geográfico, além de ter uma visão crítica sobre a realidade. Nesse momento, caberá ao professor ampliar seus horizontes e diversificar sua didática e pôr em prática tudo que foi apreendido na academia e "fazer" realmente geografia nas escolas.

\section{Procedimentos Metodológicos}

Os procedimentos metodológicos utilizados nesse trabalho foram: levantamento Bibliográfico relacionado com as temáticas trabalhadas no ensino da geografia física - conceitos bases (Espaço, Paisagem, Lugar, Território), como também - Continente Africano (características físicas), Continente Americano (características físicas), Europa (características físicas), Ásia (características físicas), China (características físicas), Japão (características físicas), Índia, Brasil, entre outras. Foi utilizado o Levantamento Empírico na coleta das informações e busca por registros fotográficos do cotidiano do ambiente escolar durante o processo de construção - aulas de campo e palestras com os professores da UFRN (Figura 4).

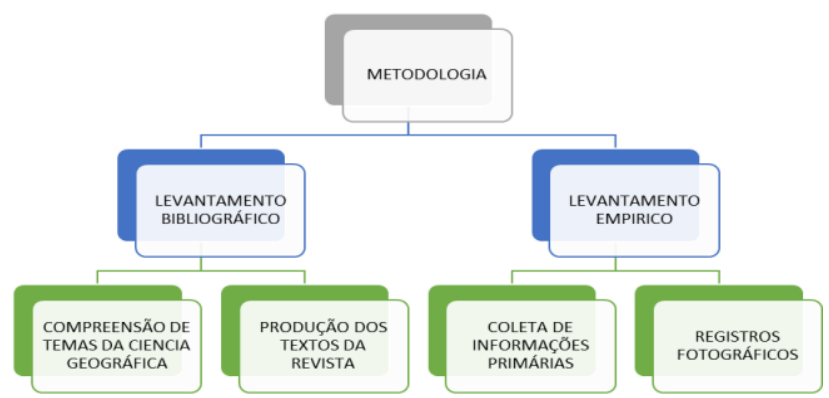

Figura 4 - Fluxograma da metodologia utilizada. Elaborado pelos autores (Ago. 12016). 
XVII Simpósio Brasileiro

de Geografia Física Aplicada

I Congresso Nacional

de Geografia Física
OS DESAFIOS DA GEOGRAFIA FÍSICA NA FRONTEIRA DO CONHECIMENTO

Instituto de Geociências - Unicamp

Campinas - SP

28 de Junho à 02 de Julho de 2017

Diante disso, os primeiros passos junto aos discentes foram reconhecer os diversos gêneros e como poderiam produzir a revista. Mas, para isso, foram necessárias a colaboração, atenção e presteza dos mesmos. Durante as aulas foram explanados os recursos discursivos, textuais e linguísticos dos textos que tratava de conteúdos da geografia física, e das reportagens veiculadas, por exemplo.

Conforme pesquisadores de didática, para elaboração do referido trabalho, cabe a todo professor permitir aos estudantes a aquisição do comportamento de leitor ativo e do escritor pela participação em situações práticas e não "por meras verbalizações". Para a realização do projeto foi necessário um período de seis meses para a execução até a culminância com o lançamento da Revista durante a Mostra da Cultura na escola e a apresentação da mesma durante o evento da MARCO - CIENTEC - mostra de ciências da Universidade Federal do Rio Grande do Norte.

\section{Resultados}

Conforme se vem acompanhando, a educação do século XXI vem contribuindo no processo de transformações pela qual a sociedade vem estabelecendo entre si, como forma de colaborar para a formação digna de um novo sujeito. Desta forma, o conhecimento é um colóquio, é um diálogo, onde a expressão de liberdade, na medida em que temos consciência de uma leitura crítica da realidade, onde a nossa reflexão deve ser um constante devir, na perspectiva de indagação e de esquadrinhar com a imaginação, sem acordo com resposta estanques e únicas.

No lançamento da proposta do projeto para as turmas, as mesmas não gostaram inicialmente, pois teriam bastante trabalho para a execução, porém com o passar das aulas e as explicações e exemplificações do formato da revista vários alunos começaram a levar a ideia a sério e começaram a interagir. $\mathrm{E}$ durante o processo do projeto percebeu-se que os discentes responderam satisfatoriamente em cada uma das etapas.

Com relação à diversidade dos conhecimentos da turma foi um ponto positivo para que a revista fosse produzida levando em consideração os diferentes aspectos e isso contribuiu para dar uma roupagem diferente em cada revista. Os discentes foram divididos em grupos, onde eles mesmos formaram os grupos entre sim e a temática da Revista foi escolhida a critério de cada grupo.

Durante o ano de 2016, foram sendo elaborados vários textos correspondentes aos trabalhos realizados na disciplina de Geografia, e isso contribuiu para a produção textual dos alunos das turmas do $7^{\circ}, 8^{\circ}$ e $9^{\circ}$ anos da Escola Municipal Professora Terezinha Paulino. Além também da produção dos textos foi inseridos no produto final as atividades de campo que foram realizadas durante o referido ano. Sabe-se que essas atividades de visitação ampliam grandemente os conhecimentos e os aprendizados. 


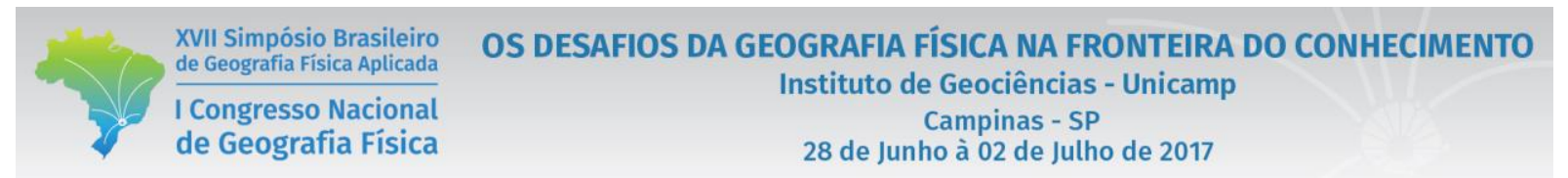

No período do $4^{\circ}$ Bimestre de 2016 foi lançado a proposta para as turmas dos $9^{\circ}$ anos $\mathrm{A}$, B e C, turno matutino, a produção de uma revista que estivesse atrelada com os assuntos estudados durante os 4 anos do Ensino Fundamental II (do $6^{\circ}$ ao $9^{\circ}$ ano). A proposta foi lançada, e os alunos conseguiram alcançar os objetivos, prepararam e produziram as revistas conforme solicitada em sala de aula com a professora de geografia e demais professores, conforme a Figura 5.

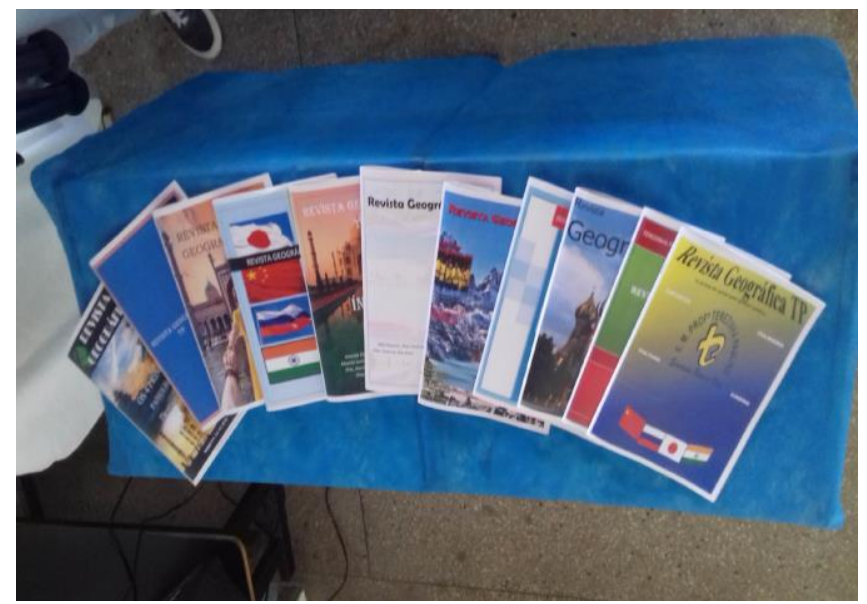

Figura 5 - Produção das revistas pelos $9^{\circ}$ anos A, B e C - referente a uma das avaliações do $4^{\circ}$ Bimestre de 2016. Foto: Ana Beatriz Maciel (Dez./2016).

No decorrer da entrega das revistas, os alunos deveriam apresentá-las com uma forma diferente Seminários Temáticos - para fazer com que os leitores (demais alunos) tivessem interesse em ler. Cada grupo trouxe uma apresentação condizente com a temática de sua revista (Figura 6).
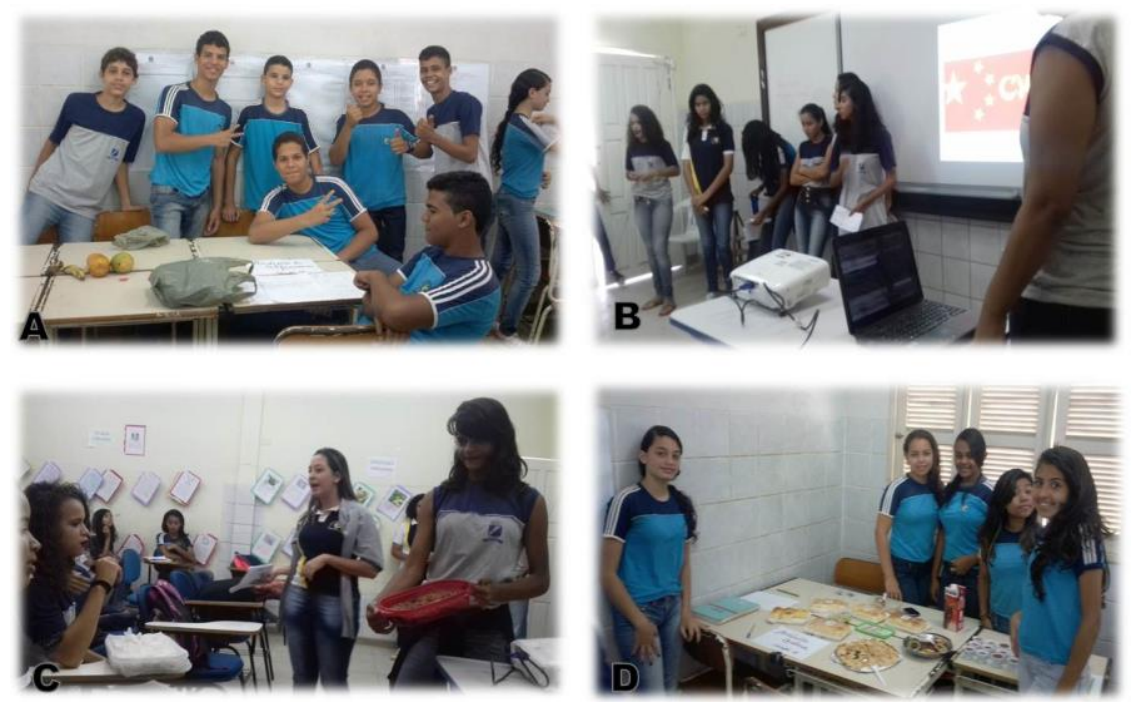

Figura 6- Apresentação dos seminários temáticos pelos alunos. Foto: Ana Beatriz Maciel (Nov./2016).

Os temas abordados nas revistas produzidas pelos alunos dos $9^{\circ}$ anos $\mathrm{A}, \mathrm{B}$ e $\mathrm{C}$ foram: $\mathrm{O}$ Continente Africano (todos os aspectos físicos); O Continente Americano (aspectos físicos e sociais); A Revista sobre a China; Características da Índia; Rússia: um país gigantesco; A Europa (aspectos físicos e sociais); o 


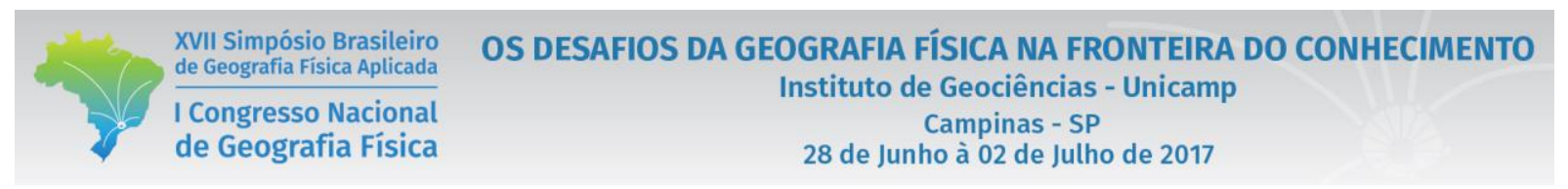

Terrorismo no Mundo; como também as aulas de campo pela cidade de Natal (Estuário Potengi, Parque das Dunas, Museu de Minérios do IFRN, Parque da Cidade, outros), conforme a figura 7.

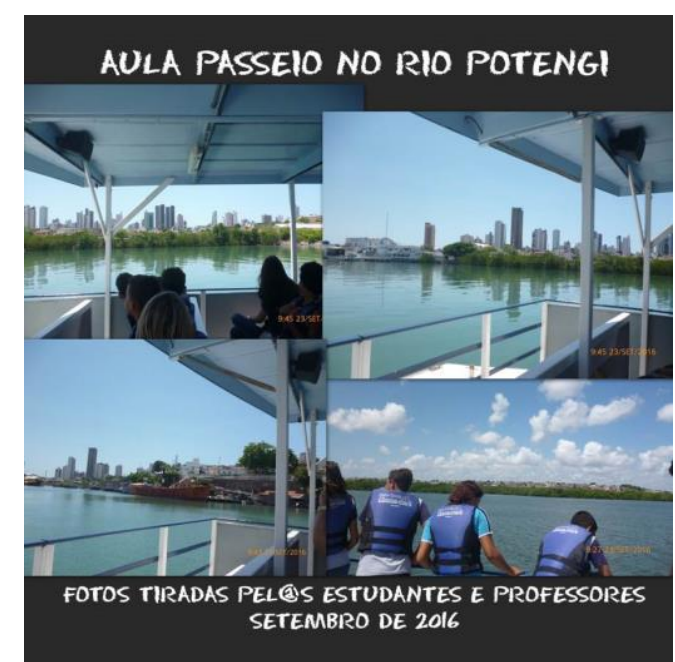

Figura 7 - Aula de Campo para o Estuário do Potengi, Natal/RN. Foto: Ana Beatriz Maciel (Nov./2016).

Como as apresentações e as produções das revistas pelos discentes foram avaliadas acima da média, ou melhor, do esperado, foi decidido que levaríamos as produções para a CIENTEC (Feira de Ciência e Tecnologia da UFRN), representando a Escola e a Secretaria Municipal de Educação de Natal e atividades desenvolvidas durante o ano inteiro - aulas de campo.

Foi montado um stand com o nome da escola e as atividades produzidas pelos docentes e alunos, durante as aulas de campos. Para finalizar esse projeto e observando o entusiasmo dos alunos e dos professores colaboradores foram sugeridos a produção de uma revista que englobasse os acontecimentos, eventos, atividades de campo, eventos na escola, projetos diversos. Contudo, foi elaborada a Revista Geográfica $\mathrm{TP}$, correspondendo ao produto final deste projeto, conforme a figura 8.
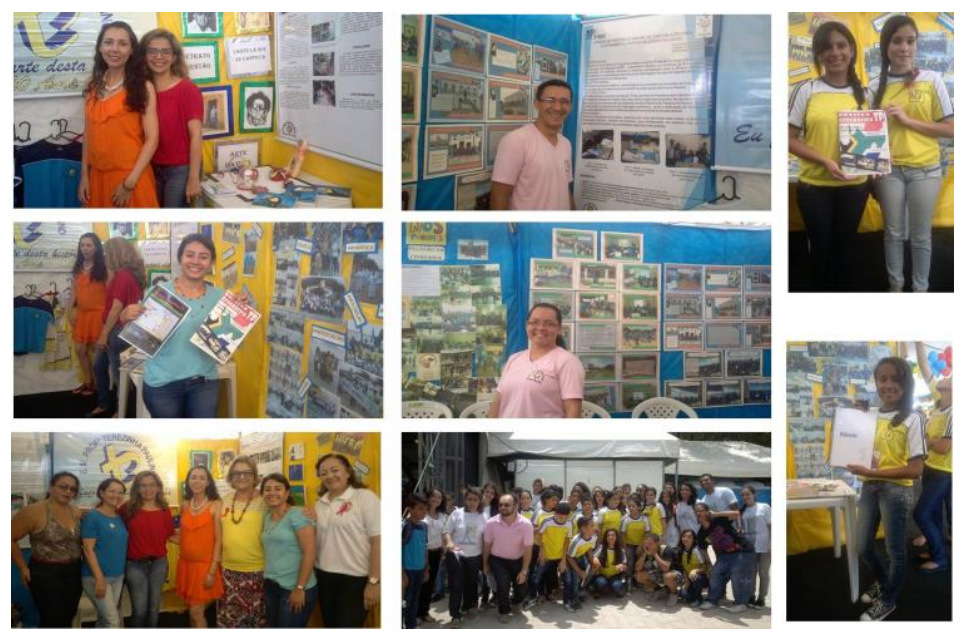

Figura 8 - Stand da Escola Municipal Professora Terezinha Paulino na CIENTEC - Natal/RN - detalhando a decoração do stand e os docentes envolvidos. Foto: Ana Beatriz Maciel (Nov./2016). 


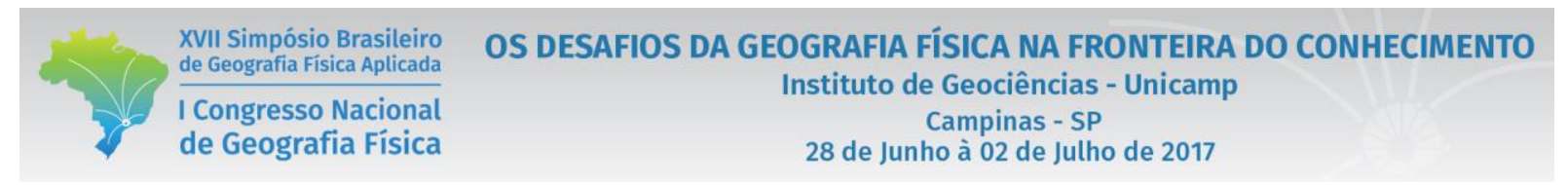

Na elaboração da Revista pôde-se contar com o auxilio dos demais professores, tanto na elaboração de textos, quanto na revisão do texto final. Acredita-se que esse produto foi bastante significativo para os organizadores quanto para os colaboradores, e principalmente para os alunos. Pode-se notar que os discentes ficaram muitos entusiasmados e ansiosos para a publicação das revistas, pois contém as suas produções textuais e/ou fotos durante as aulas de campo realizadas e inseridas (Figura 8).

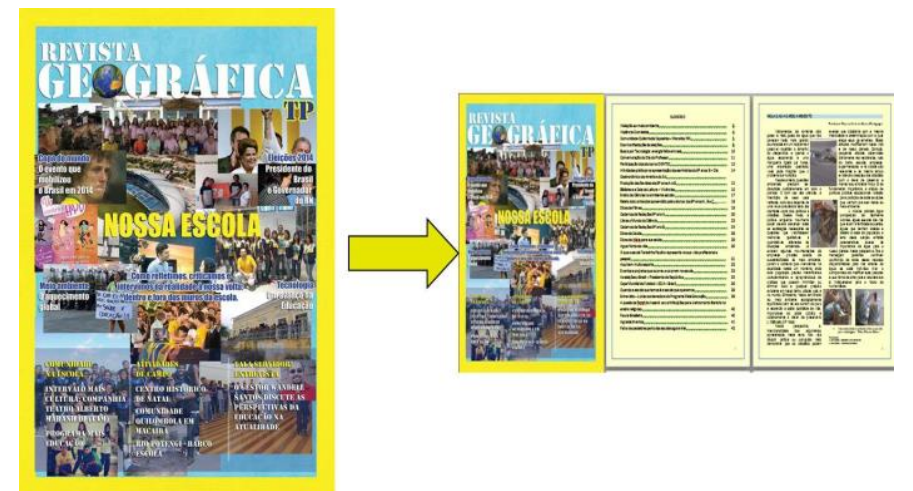

Figura 9 - Revista Geográfica TP. Foto: Ana Beatriz Maciel (Nov./2016).

Com a revista pronta e impressa, a mesma foi lançada durante o evento na escola - A MOSTRA DA CULTURA, realizada no dia 22 de novembro de 2016. Assim, como ocorre nos lançamentos de livros, revistas, a Revista Geográfica TP teve o seu lançamento. Os alunos que se envolveram um pouco mais com a elaboração e produção da mesma e produzimos uma sala para o lançamento e alguns autores puderam falar um pouco sobre a sua participação e o que esse projeto proporcionou para eles - tanto a nível pessoal como também a nível profissional.

No lançamento da revista pode-se observar a presença da Comunidade Escolar, dos Professores, dos Funcionários, dos Gestores, da Secretaria de Educação - inclusive a secretária. A presença de todos foi bastante significativa, não somente, para a escola, mas também para todos os envolvidos no projeto.

As revistas foram impressas apenas duas cópias de cada, pois o formato e o papel da revista são caros, o que inviabiliza a impressão de muitos exemplares. Mas isso, não foi problema, quem desejar consultar a revista pode procurar a biblioteca da escola, pois se encontra lá para serem lidas e apreciadas.

Com os objetivos propostos podem-se verificar vários resultados alcançados: Foi alcançada a produção de uma revista em colaboração de todos os alunos, além das revistas produzidas por cada equipe no decorrer do ano; As temáticas foram escolhidas por cada grupo, onde tiveram a livre escolha de temas, desde conteúdos apreendidos do $6^{\circ}$ ano até o $9^{\circ}$ ano referente à Ciência Geográfica com ênfase na geografia física, mas que teriam que fazerem uma relação com outras disciplinas. Podem-se identificar em cada revista produzida conteúdos desde história, ciências, artes, esporte, entre outros; A produção desse 
material proporcionou a sociabilização entre os alunos, onde os mesmos tiveram que se reunirem diversas vezes para elaborar o material, para fazerem os registros fotográficos para por na revista, buscarem patrocinadores para a impressão do material, entre outras formas; Foi observado também a interação da comunidade escolar e a escola no momento de auxiliar os alunos na confecção dos materiais e no auxilia impressão, dando a oportunidade a esses alunos de ampliarem os seus conhecimentos e se verem como produtores e editores de textos, revistas, entre outros; Nesse projeto propõe que os discentes mostrem as suas habilidades sejam quais forem, como: desenhos, leituras, arte digital, registros fotográficos alterados a sua maneira, produções textuais.

Como todo projeto, durante a sua execução aparece alguns contratempos e/ou dificuldades enfrentadas no decorrer do percurso. Um exemplo de dificuldade enfrentada foi como conseguir a impressão da revista de cada grupo. Para contornar essa questão financeira, sugeriu-se aos alunos que fossem pedir patrocínio aos comerciantes, feirantes, prestadores de serviços da área, onde os mesmos seriam fotografados e inseridos na revista como patrocinadores, assim envolveram os comerciantes da área de sua residência, como também a comunidade local que serviu como elo junto à comunidade local.

Os momentos significativos durante a execução do projeto foram vários, como os citados a baixo:

- A interação entre os alunos, entre os alunos e os pais e a escola-aluno-comunidade por meio de visitas a escola para sugerir temáticas para a revista, assim como para prestigiar o seu filho.

- Apresentação e lançamento da revista pelos alunos - deixou os professores bastante satisfeitos com os resultados.

Assim, pode-se afirmar que os discentes participantes do referido projeto tiveram os seus conhecimentos ampliados, não somente em Geografia, mas também com relação à produção textual, questões históricas, lazer, esporte, entre outros.

Assim, proporcionou o desenvolvimento intelectual dos alunos dentro das suas capacidades, habilidades e limitações, não impondo o que é obrigado, e sim, deixando-os livre para criarem; Pode-se perceber que o aluno começou a ter um olhar diferente para essa produção e outras na sala de aula, pois perceberam o quanto é importante o hábito de leitura e escrita. E o conhecimento de mundo é tão importante quanto aprender a ler. A revista também teve a relevância de mostrar para o discente que é capaz de produzir o que quiser, basta ter vontade e entusiasmo para querer produzir.

O projeto Revista Geográfica TP ficou entre os 50 projetos finalistas do Brasil - $19^{\text {a }}$ Edição do Prêmio Educador Nota 10 da Fundação Victor Civita de 2016 com apoio do Canal Futura e Nova Escola dos mais 4.221 projetos submetidos ao prêmio (Figura 10). 


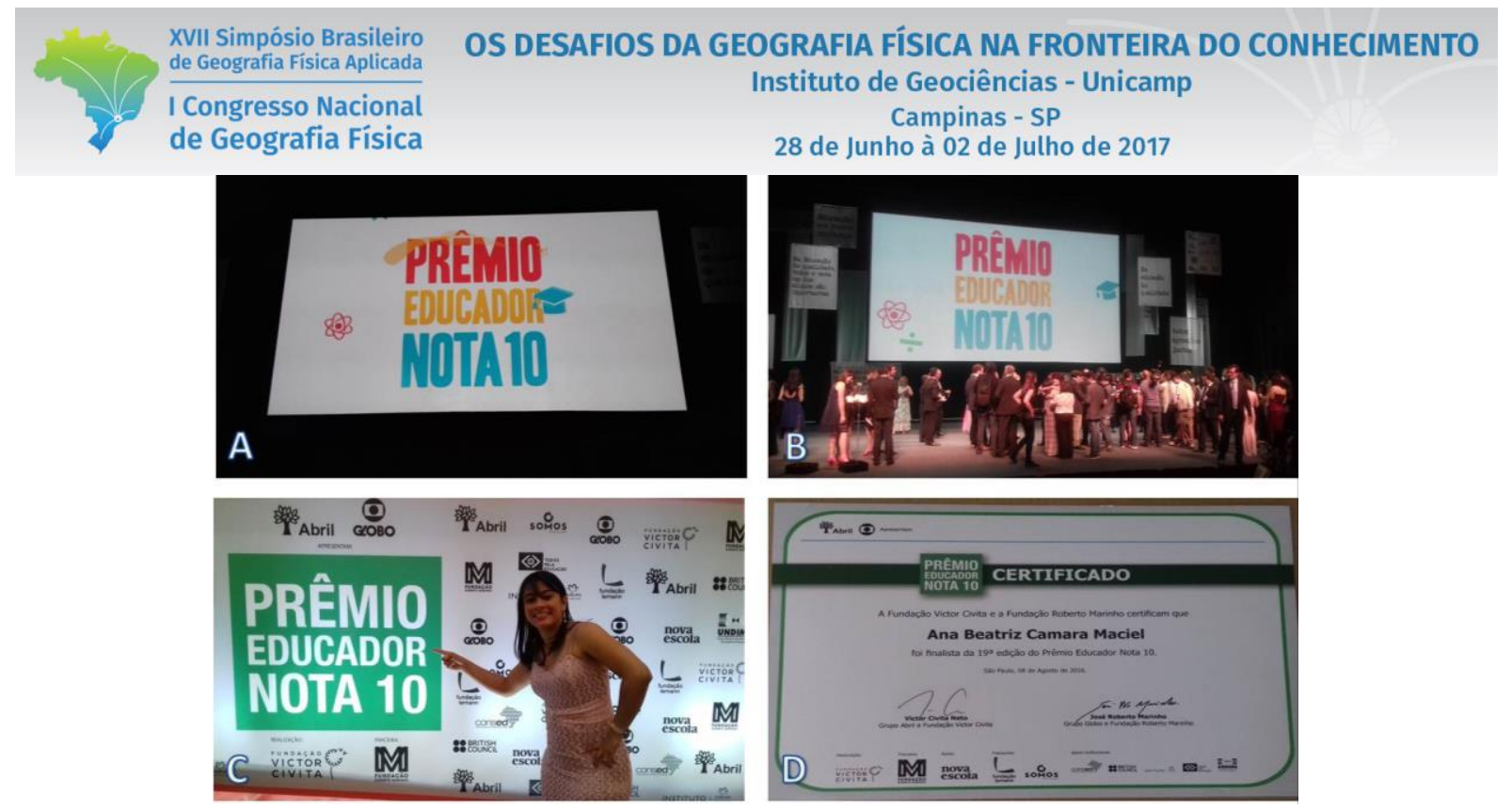

Figura 10 - 19ª Edição do Prêmio Educador Nota 10 da Fundação Victor Civita de 2016.Foto: Ana Beatriz C. Maciel (Out/2016).

Teve-se a oportunidade de participar da Cerimônia de Premiação - no dia 17 de outubro, em São Paulo Teatro Santander, na qual fomos finalistas (somente 2 projetos do Município de Natal/RN foram finalistas), onde receberemos uma homenagem na melhoria do ensino da rede pública do Brasil e fomos representando a Secretaria Municipal de Educação (SME) e os professores da rede básica.

\section{Considerações Finais}

A avalição da aprendizagem foi realizada por meio de apresentações de cada grupo com a sua revista e também o lançamento das mesmas em alguns eventos locais, como MARCO (Feira de Ciências da Rede Municipal de Natal), CIENTEC (mostra científica e cultural da UFRN), Mostra da Cultura da Escola Municipal Professora Terezinha Paulino.

A avaliação da prática docente é realizada pela gestão e coordenação da Escola, dando o parecer ao projeto, por meio da exposição do referido projeto. Durante o projeto verificou-se alguns pontos que não poderiam ser mais da mesma forma, como por exemplo: ter um tempo maior para a preparação do material, pois com as aulas para exposição do conteúdo, o tempo para a elaboração ficou reduzido, e isso influenciou no acabamento da produção, deixando alguns problemas, como erros de português. Diante da realização desse projeto, surgiram várias ideias para novos projetos e novas perspectivas dentro de uma educação de qualidade com ênfase na Geografia Física.

Com a execução desse projeto observou-se que os alunos são capazes de realizar e produzir coisas das mais diversas proporções basta apenas incentivá-los, instigá-los a buscar o que desejam. Mesmo nas dificuldades de acessos a determinados equipamentos e/ou materiais, podemos contribuir da melhor forma possível para levar o sucesso do aluno. Durante a realização do projeto, observaram-se vários pontos positivos, tais como: interação dos alunos com os professores, a comunidade escolar; Entusiasmo dos 
discentes na produção da revista, na busca por patrocínio, na produção textual, na forma de imprimir, entre outras formas; e, as aulas de geografia física ficaram mais dinâmicas e tiveram mais interações entre os alunos e o professor.

Os desafios são muitos, principalmente quando se tem que trabalhar em dois e até às vezes em três expedientes para ter uma renda mínima para sobreviver, e isso faz com que os professores não tenham tanto tempo para se dedicar a esses projetos que são de extrema importância para o movimento da escola, dos discentes e da comunidade local.

Diante da experiência vivenciada na elaboração, execução e culminação do projeto da construção de uma Revista acredito que pode se replicada para outros professores, como também pode ser ampliada e ajustada de acordo com as especificidades de cada cidade ou bairro onde a escola seja escolhida.

Pode-se verificar que o projeto é bem simples de ser feito, basta apenas vontade profissional em busca de novas práticas pedagógicas voltadas para o ensino-aprendizagem em geografia física, incentivo ao ensino dos alunos em busca da melhor forma de aprendizado e fixação dos conteúdos trabalhados em sala de aula. Então, verifica-se que basta ter vontade de ensinar e incentivar aos alunos que todos são capazes de produzir, elaborar o que desejar. Nesse sentido, o professor, nesse momento é um instrumento de instigar as habilidades e as competências dos nossos alunos em busca do objetivo específicos.

Os professores que se inspirarem no projeto, verificarão que o aprendizado dos discentes se tornam mais concretos, profundos e consistentes. Os alunos buscam incentivos a todo o momento, e o professor é a peça chave para o desenvolvimento desse aluno. A Escola Terezinha Paulino de Lima conta com a presença de vários projetos, todos com o intuito de interagir, ampliar os conhecimentos, sociabilizar, entre outros. Assim, o professor ao aplicar o projeto tenha a certeza que os discentes não se esqueceram do trabalho dado para elaborar a revista, a ausência de dinheiro para produzir a revista.

\section{REFERÊNCIAS}

ADAS, Melhem; ADAS, Sergio. Expedições Geográficas: Geografia. 2.ed. São Paulo: Editora Moderna. 2014.

BOLÓS, M.I.C. Problemática actual de los estudios de paisaje integrado. Revista de Geografia. Barcelona, v. 15 , n. 1-2. 1981. pp. 45-68.

BRASIL. Secretaria de Educação Fundamental. Parâmetros curriculares nacionais: introdução aos parâmetros curriculares nacionais / Secretaria de Educação Fundamental. - Brasília: MEC/SEF, 1997. $126 \mathrm{p}$.

FREIRE, Paulo. Pedagogia da autonomia: saberes necessários à prática educativa, Paz e Terra, 2009. 
GUERRA, Antônio José Teixeira; MARÇAL, Mônica dos Santos. Geomorfologia Ambiental. Rio de Janeiro: Bertrand Brasil, 2006. 192 p.

JARDI, M. Paisage: ¿uma síntesis geográfica ¿ Revista de geografia.Barcelona. v. XXIV. 1990. p. 43-60.

LIBÂNEO, José Carlos. "Reflexividade e formação de professores: outra oscilação do pensamento pedagógico brasileiro?", In: PIMENTA, Selma Garrido, e GHEDIN, Evandro: Professor reflexivo no Brasil: gênese e crítica de um conceito. São Paulo, Cortez Editora, 2002.

LIBÂNEO, José Carlos. Didática. São Paulo: Cortez, 1994. (Coleção Magistério $2^{\circ}$ Grau. Serie formação do professor).

OLIVEIRA, Lívia de.; MACHADO, Lucy Marion Calderini Philadepho. $3^{\circ}$ Encontro Interdisciplinar sobre o estudo da paisagem. Rio Claro: UNESP, 1998. v.1. 154 p. (Cadernos Paisagem/Paisagens).

RAMA, Angela. PAULA, Marcelo Moraes. Jornadas: Geo - Geografia. 2.ed. São Paulo: Saraiva, 2013.

SANTOS, Milton. Espaço e Método. São Paulo: Nobel, 1985.

SANTOS, Milton. Metamorfose do espaço habitado. São Paulo: EDUSP, 2008. HUCITEC, 1988.

SANTOS, Milton. Técnica, espaço, tempo. São Paulo: Editora Hucitec, 1994.

SAUER, C. O. A morfologia da paisagem. 1925. In: ROSENDAHL, Z.; CORRÊA, Roberto Lobato. Paisagem, tempo e cultura. Rio de Janeiro: Ed. UERJ, 1998. pp.12-74.

SOTCHAVA, V. B. Estudos dos Geossistemas: Método em Questão. IGEO/USP. São Paulo, 1977. VEDOVATE, Fernando Carlos. Projeto Araribá: Geografia. 3.ed. São Paulo: Editora Moderna. 2013. 